\title{
Improved Bike Helmet Takes Top Prize at e-Fest
}

\author{
James Beal (EIX.org | e-Fest® | FamilyBusiness.org)
}

KEYWORDS: Entrepreneurship, Innovation.

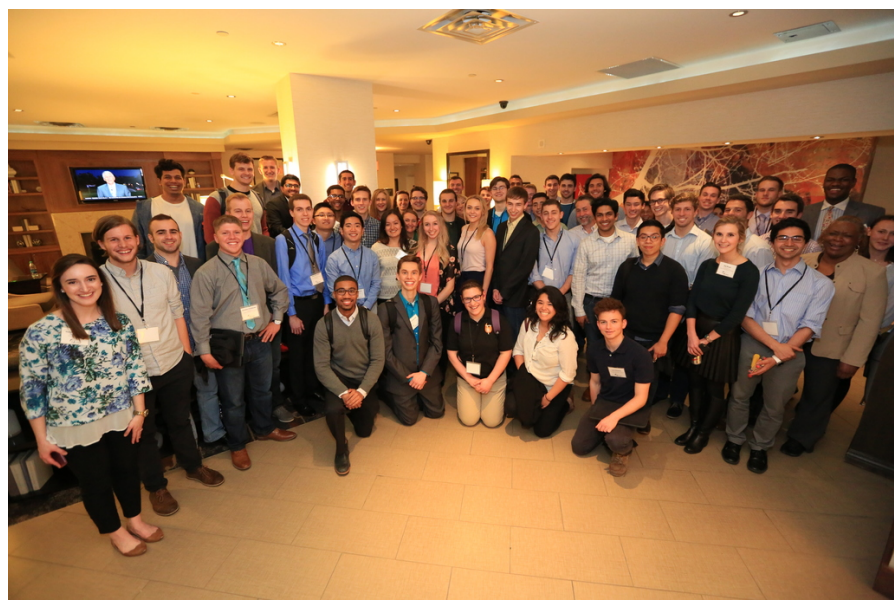

Teams of student entrepreneurs gathered at the Schulze School of Entrepreneurship in Minneapolis April 6-8, 2017 for e-Fest, which gave them the chance to compete for more than $\$ 250,000$ in prizes for themselves and their universities.

To learn more about eFest, EIX's competition for undergraduate business ideas, click here (https://eix.org/e-fest-guide/) .

MINNEAPOLIS, APRIL 9 -- Two engineering students from Virginia Tech have won the $\$ 100,000$ top prize at eFest for their stylish, ultra-portable and safe bicycle helmet.

The helmet, made by their venture "Park and Diamond," aims to save lives by offering the world's millions of bicyclists protective headgear that they will actually want to wear. Students David Hall and Jordan Klein developed a helmet that resembles a baseball cap rather than the bulky, clunky, hard-to-stow helmets on the market today. Along with being attractive and packable, the helmet is made from advanced composites and has been performance tested using Consumer Products Safety Commission standards.

Said e-Fest judge Susan Otten: "The mission of this ultra-portable bicycle helmet is to improve cycling safety, spawned from a family member's hit-and-run bike accident while riding without a helmet. As an innovator reinventing a market where current designs haven't changed since the '90s, this helmet seamlessly fits into your life by having a compact form factor easily stored on the bike or carried in a backpack/bag when not in use. The application of composite material allows the helmet to have a thin profile and even greater safety ratings, transforming helmets from stigmatized ugly to stylized self-expression. This team already has an eye to their future growth, with ski/snowboard helmets as the next target. The judges felt this idea was a game changer with a cause."

In their presentation, Hall and Klein cited their own careful, rigorous research that showed that most people who don't wear bicycle helmets say they don't like how they look. Uncomfortable fit and portability are other major deterrents, they found.

"We've designed a helmet that seamlessly fits in your life, rather than being a bulky, inconvenient thing that you carry around with you," they added. "We are creating something that has gone from stigmatized to stylized."

Along with the students' prize, e-Fest also awarded Virginia Tech $\$ 10,000$ to support their entrepreneurship education programs.

\section{Judges praise all finalists}

The second prize at e-Fest went to Northeastern University students Johnny Fayad and Ali Kothari for "Eat Your Coffee," a tasty caffeinated snack for students and others who need a caffeine fix but don't have time to pick up coffee. That innovation won $\$ 50,000$, with an additional $\$ 5,000$ going to Northeastern.

"This energetic duo presented with confidence and clarity," said judge Elaine Peet. "With few coffee grounds at the bottom of their cup, they identified their main threat is growing too quickly -a tough problem to 
have. The judges all agreed this innovative idea has great potential as a highly successful business."

Third place went to Chris Maurice of Auburn University for YellowCard, a platform providing easy access to 86 digital currencies, making moving money painless and saving families thousands of dollars every year in global remittances. Maurice won $\$ 25,000$ and an additional $\$ 5,000$ for Auburn. "The movement of money internationally can be a barrier for many people, as well as very expensive," said judge Ann Jensen. "There was a lot of positive reaction from the judges to this presentation and product."

These top three teams were chosen from 25 finalists, selected from an original pool of more than 160 teams from 81 schools who submitted seven-minute videos and 12 slides describing their business ideas. The student finalists traveled to Minneapolis for e-Fest, held at the Schulze School of Entrepreneurship, Opus College of Business at University of St. Thomas. The featured speakers included Best Buy founder Richard M. Schulze and "Shark Tank's" Daymond John, founder of FUBU, the multi-billion dollar clothing and lifestyle brand.

Judges praised the overall quality of the 25 entries. "The teams were articulate, prepared and super smart about their products and services," they observed. "We were impressed with the innovation and problem solving capacity of the teams. The colleges are doing a great job of preparing student entrepreneurs."

\section{Advice for Students}

Along with picking the top three teams, the e-Fest judges also offered some general advice for the students as they continue their entrepreneurship journey. The takeaway:

\section{Learn from others' mistakes}

By definition, students are in school and may not have had the opportunity to fail (yet) in business. Find and build relationships with those who have more experience and are willing to share their wisdom.

\section{Align with those who are (street) smarter than you}

Launching a business is complex and you don't have to know it all or do it all. While you are expert on your product or service, you probably know less about sourcing, manufacturing, branding, marketing, investor pitching, finances, operations, distribution, customer support, reverse logistics, contracts, etc.

It's not what you know, it's who you know Find advisors you trust, including your parents - they are your biggest fans and want to see you succeed beyond your wildest dreams - and treat them as the valuable resource they are. They will save you time, money and most importantly, a ton of disappointment.

\section{Keep your balance}

Time will always be your most limited, most precious resource. Problems will always be there waiting to be solved. Do not (repeat, do NOT) overstress, overwork, over-worry. Remember who your friends are and ask them to hold you accountable to take a break, reset and rethink. All the glory, fame and fortune is not worth losing sleep or losing a friend.

\section{More about the e-Fest finalists}

The largest undergraduates-only business plan competition (as measured by the size of the cash awards), e-Fest was co-sponsored by the Schulze School of Entrepreneurship (http://www.stthomas.edu/business/schulze-school/) , Opus College of Business at the University of St. Thomas in Minneapolis and EIX.org (https://eiexchange.com/), an online learning platform for entrepreneurs, students and professors. More information about the rules and judging can be found here(https://eiexchange.com/e-fest)

(https://eiexchange.com/e-fest) .

Below is the full list of 2017 e-Fest finalists.

\section{Boost Linguistics}

Drexel University, Philadelphia, PA

Team: Ethan Bresnahan, Alex Dodson, Jeff Nowak

Advisor: Chuck Sacco

The innovation: Boost Linguistics is a program that uses artificial intelligence to help online content marketers use the best wording for audience engagement.

\section{Caddy-Clean}

Quinnipiac University, Hamden, CT

Team: Joshua Macari, Kyle Freitas 
Advisor: Dale Jasinski

The innovation: Caddy-Clean is an all-in-one tool that snaps easily onto a golf cart and can be fetched while on the course to clean off clubs and golf cleats.

\section{Convey Software}

University of Illinois - Urbana Champaign

Team: William Widjaja, Cody Pawlowski

Advisor: Chase Bonhag

The innovation: Convey Software is a tool that analyzes sentiment on social media to predict trends.

\section{Eat Your Coffee}

Northeastern University, Boston, MA

Team: Johnny Fayad, Ali Kothari

Advisor: Kimberly Eddleston

The innovation: "Eat Your Coffee," is a breakfast bar loaded with caffeine for students and others who don't have time to pick up coffee but need their caffeine hit.

\section{ExpressionMed}

University of St. Thomas, Minneapolis

Team: Meghan Sharkus

Advisor: Laura Dunham

The innovation: ExpressionMed are colorful patches featuring cartoons and friendly designs to help children with diabetes overcome the fear and stigma of using a wearable insulin pump.

\section{FinMoto}

University of St. Thomas, Minneapolis

Team: Sam Rystrom

Advisor: Laura Dunham

The innovation: This is a "virtual financial partner" for young people. Securely linked to their bank accounts, it helps them manage their money, plan for the future, and make intelligent decisions.

\section{GeoSwap}

\section{Western Michigan University, Kalamazoo, MI}

Team: Nicolas Theoret, Brandon Chiddester

\section{Advisor: Lara Hobson}

The innovation: Jacket360 is a device, worn on a bicyclist's sleeve, that vibrates when a car is approaching from behind, alerting bicyclists without requiring that they turn around to see the car.

\section{Level Lacrosse - Feeder}

Western Kentucky University, Bowling Green, KY

Team: Muamer Razic 


\section{Advisor: Dawn Bolton}

The innovation: This device, the size of a pack of gum, helps lacrosse players and coaches monitor individual performance and track their growth. It fits inside the lacrosse stick and feeds into a mobile device, similar to how a FitBit works.

\section{NextStep}

University of New Hampshire, Durham, NH

Team: Sam Warach, TJ Evarts, Max Miller

\section{Advisor: Andrew Earle}

The innovation: NextStep is a Software As a Service (SAAS) innovation that connects recovering drug addicts with certified sponsors who can provide mentorship and connect addicts with resources that help them heal.

\section{Orindi Ventures}

Grand Valley State University, Grand Rapids, MI

Team: Jordan Vanderham, Zoe Bruyn

Advisor: Kevin McCurren

The innovation: The Orindi Mask is a device that helps asthmatics and others with breathing problems who must work outside, by warming the air they breathe.

\section{Park \& Diamond}

Virginia Tech, Blacksburg, VA

Team: David Hall, Jordan Klein

Advisor: Dick Daugherty

The innovation: An attractive, packable bicycle helmet that resembles a baseball cap and gives bicyclists protection without bulk.

\section{PeeWee Packs}

Grove City College, Grove City, PA

Team: Hannah Vaccaro, Ross Harrington

Advisor: Yvonne English

The innovation: PeeWee Packs are flushable wipes that change color and reveal pictures when a toddler uses them in the toilet. The goal is to motivate the toddler to visit the toilet more often and improve potty training.

\section{Phlex-xGoggles}

University of Florida, Gainesville, FL

Team: Luke Torres

Advisor: Michael Morris

The innovation: This wearable device - similar to a glasses frame -- and mobile app helps competitive swimmers and their coaches and teammates track, compare and share their training progress. The device attaches to the swimmer's goggles.

\section{Sensor4Safe}

Seton Hill University, Greensburg, PA

Team: H. Fitzgerald Robertson II, Austin Sheridan, Melanie Ansell, Dhiraj Totwani

Advisor: Lyzona Marshall

The innovation: Sensor4Safety is a device and app designed to reduce the harm to babies and pets accidentally left in vehicles. It monitors movement and temperature in the vehicle and sends messages to the owner's smart phone.

\section{Simplifeye}

NC State University, Raleigh, NC

Team: Cortney Cox

Advisor: Lewis Sheats

The innovation: Simplifeye is a stencil that the user can use on the eyelid while applying liquid eyeliner, for that perfect "cat eye" look.

\section{SpeechMasterPro}

Western Michigan University, Kalamazoo, MI

Team: Daniel Floyd

Advisor: Lara Hobson

The innovation: SpeechmasterPro is a tool, resembling a whistle, that helps people with speech disorders become clearer, more effective speakers. 


\section{Strokeflow}

John Hopkins University, Baltimore

Team: Sam Einhorn, Zack Bredl, Emily Hadley, Sofia Diez

Advisor: Phil Phan

The innovation: Strokeflow is a mobile app that allows medical teams to easily track the treatment of stroke patients, as well as amass data that benefits stroke research and patient health. The goal is to improve outcomes, save time and generate better data about what works and what doesn't. The students have told us that it will be tested at JH's medical center this spring.

\section{Tibah}

Binghamton University, Binghamton, NY

Team: David Axelrod, Mauricio Morales

Advisor: Ken Mcleod

The innovation: "Tibah" is a mobile app designed to help fitness enthusiasts stay motivated and trainers keep track of client data.

\section{Torridity Instrument Heating Solutions \\ LLC}

University of Wisconsin - Madison, WI

Team: Lizzy Svigelj, Austin Kyle, Zach Klayman

Advisor: Michael Williams

The innovation: Their device prevents sensitive musical instruments from freezing up when they are outside in cold weather, an innovation designed to help student bands and others.

\section{Upright Kids}

University of Wisconsin - Oshkosh

Team: Dylan Parks, Brad Ploch

Advisor: Jordan Rhodes

The innovation: The team has invented an inexpensive, ergonomic standup desk for children to help them be less fidgety in school.
Babson College, Babson Park, MA

Team: James Cheng, Thomas Lehman

Advisor: Yashiro Yamakawa

The innovation: Vowel Inc. is an app and service that scrutinizes the user's monthly household expenses, looks for less expensive options and actually negotiates with the providers for a better deal.

\section{Yellow Card}

Auburn University, Auburn, AL

Team: Chris Maurice

Advisor: Lakami Baker

The innovation: YellowCard is a platform providing easy access to 86 digital currencies, making moving money painless and saving families thousands of dollars every year in global remittances.

Click here(https://eiexchange.com/e-fest) (https://eiexchange.com/e-fest) for information about the 2018 e-Fest.

\section{Vowel Inc.}

